pepsin in the urine, and the proper method of administering pepsin by the mouth form the text for three other lectures. The cachexia of gastric carcinoma is correlated with an excess in the blood serum of toxic albuminous bodies produced by a proteolytic ferment resembling erepsine, which is secreted by the growth; as a defensive measure antiproteolytic bodies are manufactured in the serum, and as this process is favoured by the administration of trypsine this means of treatment is adrocated. Evidence is brought forward to show that the grave anaemia of gastric cancer is due to the haemolytic effects of albuminous and lipoid bodies in excess in the serum, and to counteract this the administration of cholesterol or more simply of yolk of egg is recommended. Other chapters are devoted to plastic linitis (carcinomatous) of the pelvic colon, the gastric symptoms of gall stones, phlegmonous gastritis (with the details of a case due to gassing), and the dietetic treatment of gastric disorders; but enough has been said to show the stimulating character of Professor Loeper's work.

\section{NOTES ON BOOKS.}

Pharmacists and dispensers must have a ready memory for a great number of facts such as the nature of the active constituents in galenical compositions, their proportions in compounded articles, and the magnitudes of medicinal doses. These must for the most part be acquired by simple effort of memory. Were this not the case there would have been little excuse for the production of GWYNETH PENNETHORNE's Guide to Assistant's Examination in Materia Medica and Pharmacy, ${ }^{8}$ for the contents of the volume consist chiefly of those memoranda in their briefest form; the work can hardly be said to teach the subjects of its title on an educational plan. Something may perhaps be said for beginning a subject with the facts to be memorized and taking up a more rational scheme of study afterwards. Thus applied this book may be useful since its contents are substantially free from inaccuracy. It has, moreover, a budding element of merit above that of such books as are intended to do no more than circumvent the tests expected from the examiner; a number of hints given on methods of dispensing are well conceived. A moderate addition of explanatory matter would ha ve greatly enhanced the value of the book. For example, the article on milk sugar contains the sentence, "It is used as a diluent of powerful drugs," but nothing is said to indicate the properties which render milk sugar the most suitable of materials for that purpose, although one or two short sentences would have sufficed. Obviously a more complete treatise will be required by those who are to escape the dangers of possessing only a little knowledge, but an edition of this work interleaved with blank pages for the notes of the user might be found serviceable by a considerable number of students of materia medica and pharmacy.

Dream Fairies ${ }^{9}$ is the title of a collection of enjoyable verses written for children by Dr. T. WILSON PARRY, and illustrated in black and white by Mr. Gerald Aylmer. The little volume is redolent of the English countryside, and should prove a delight to the innumerable children who love birds, butterflies, brooks; frogs, flowers, and fairies. Mr. Aylmer's apt sketches really illustrate the text, and he shows an excellent sense of design in his pen-and-ink drawings. Personally, we liked his pictures of little girls (as on p. 4) better than his fairies, but we confess that a child who was shown the drawings greatly preferred the fairies to the children.

Under the title Massage and Exercises Combined,10 a Mr. ALBRECHT JENSEN of New York has published an illustrated account of a course he has devised of mild gymnastic exercises, combined with self-massage and breathing exercises. The book is addressed rather to the general priblic than to the medical profession, and contains a number of superfluous adornments such as a display of high-sounding adjectives on the title-page and a portrait of the author on art paper as a frontispiece. The exercises themselves, however, are not without merit, being simple and requiring no undue straining nor any gymnastic apparatus.

ERRATUM.-The price of Dr. L. Emmett. Holt's Diseases of Infancy and Childhood, published by Messrs. D. Appleton and Co., is $35 s .$, not $6 \mathrm{~s}$., as by a clerical error was stated in our issue of September 23 rd at page $5 € 6$. 'Guide to Assistant's Examination in Materia Medica and Pharmacy,
Apothecaries' Hall. By Gwyneth Pennethorne. With a Preface by P. A. Ellis Richards, F.I.C., F.C.S. London: Baillière, Tindall, and Cox. 1922 . (Fcan. 8vo, pp. $x i+\varepsilon 66$. 6s. net.)

Hamilton, Fairies. By T. Wilson Farry. London: Simplin, Marshall, Hamilton, lient, and Co. 1922. (Demy 4to, pp. 34; illustrates. 2s 6arshall, ${ }^{10}$ Massage anid. Exercises Combined. pa. 34; illustrated. 2s. 6d. net.) A. Jensen, Box 73, G.P.O., New Yurk City. 1920. (Sup. roy.8\%o, pp. 93: 86 illustrations. 2.50 dols.)

\section{THE ORGANIZATION AND FINANCE OF VOLUNTARY HOSPITALS.}

Sir Napier Burnett's Report.

Sir Napier Burnett, Director of Hospital Services for the Joint Council of the Order of St. John and the British Red Cross Society, has just published his third annual report ${ }^{1}$ on the voluntary hospitals in Great Britain, excluding Loudon. This report contains the result of his examination of the statistics of the voluntary hospitals for the year 1921. It deals not only with the financial status of the hospitals, but also with the quality of their work and their relative effi. ciency. As the hospitals in the London area are under the supervision of the King Edward VII Hospital Fund they are not included.

The object of these annual reporis is thus twofold-namely, to present to the public detailed information regarding the financial position of the voluntary hospital system, and to assist hospital governors and administrators with informa! ion whereby they may ascertain how their hospital position compares with the group averages of other comparable insti. tutions. As regards the financial side of the problem, it is interesting and encouraging to note that in the year under review the majority of the provincial voluntary hospitals were able to pay their way for the first time since the war. As prices were high at the beginning of 1921 and unemployment was rife during the latter part of the year, the hospitals may now look forward with rather more confidence to the future, and it is expected that the figures for 1922 will show au even better position.

\section{Classification of Hospitals.}

The classification adopted in the present as in prerious reviews is according to size or the number of available beds; the hospitals are further grouped into general and special, and the latter are subdivided according to the age and sex of patients and to the nature of the ailments treated-for example, eye or ear and throat hospitals. Sir Napier Burnett considers, however, that such classification is unsatisfactory and that a new method of grading hospitals is required. Thus, two hospitals with the same number of beds sliow in their annual reports that one has cost 50 per cont. more than the other, and the impression produced when they both appeal to the public for support may be that the one hospital is extraragaut and inefficiently administered in comparison with the other. The true position may be, on the other hand, that the hospital showing the higher cost is really the more economical, in that it is supplying a much fuller seivice to the public than its neighbour. One, for instance, may be provided with a full range of special departments, including bacteriological and pathological laboratories for the investigation of the causation of disease, while the other hoipital merely acts as an infirmary for sick foll and has few facilities for the study of disease. Such hospitals are not at all com: parable from the point of view of service rendered to the community, and yet as they are graded at present, according to size, the public have not the knowledge of how to discriminate.

Sir Napier Burnett considers that hospitals may be graded according to the quality of the work that they do and the facilities they provide for carrying out such work. The group of hospitals known as teaching hospitals, in that they are associated with medical schools, should, in his opinion, be graded as a group apart from all other hospitals. Excluding the teaching hospitals, he suggests that otlier hospitals could be graded into classes $\mathrm{A}, \mathrm{B}$, and $\mathrm{C}$, according to their general standard of equipment and laboratory facilities, etc. On such a basis the subscribing public would have the knowledge to enable them to appreciate why the class A hospital is necessarily more expensive than one in class $C$.

It may be remembered that a few years ago the Amcrican College of Surgeons decided to carry ont a survey of the hospitals in the United States and Canada with 100 or more beds. Of these there were 697, and the object of the survey was to ascertain how many of the hospitals conformed to tho minimum standard of efficiency laid down by the Collegenamely, the keeping of proper clinical records by the

1 Third Annual Report on the Voluntary Hospitals in Great Rrituin (excluding London) for the Year 1921. By Sir Napier Burnett, K. B.E. M.D., F.R.C.S., F.R.C.P., with an introductory note by the Hon. Sir Arthur Stanley, G.B.E., C.B., M.V.O. Publisied by the Joint C uncil of the Order of St. John and the British Red Cross Society, 19, Berkeley
Street, London, W.1. Price.ss. 